\title{
SOCIALIZAÇÃO EM UMA INSTITUIÇÃO TOTAL: IMPLICAÇÕES DA EDUCAÇÃO EM UMA ACADEMIA MILITAR
}

\author{
GiULIANA FRANCO LEAL ${ }^{*}$
}

\begin{abstract}
RESUMO: Neste artigo, aborda-se o processo de socialização secundária dos cadetes da Aeronáutica brasileira. A partir de pesquisa de campo qualitativa e documental, descrevem-se e discutem-se os objetivos e a prática dessa socialização, com especial ênfase às tensões de uma instituição total (tal como definida por Erving Goffman) que, contraditoriamente, destina-se a formar profissionais com certo grau de autonomia individual. Problematizam-se, então, as consequências do processo de socialização, tanto as esperadas como as não planejadas pela instituição.
\end{abstract}

Palavras-chave: Socialização secundária. Educação militar. Instituição total.

\section{SOCIALIZATION IN A TOTAL INSTITUTION: IMPLICATIONS OF EDUCATION IN A MILITARY ACADEMY}

ABSTRACT: In this paper, we discuss the process of secondary socialization of cadets in the Brazilian Air Force. We use qualitative research to describe and discuss the goals and practices of this socialization process, paying attention to the tensions in a total institution (as defined by Erving Goffman) that, paradoxically, is intended to educate professionals to show some individual autonomy. We then problematize the socialization process consequences, both expected and unplanned by the institution.

Key words: Secondary socialization. Military education. Total institution.

\section{SOCIALISATION DANS UNE INSTITUTION TOTALE: LES IMPLICATIONS DE L'ÉDUCATION DANS UNE ÉCOLE MILITAIRE}

RÉSUMÉ: Dans cet article, on présente le processus de socialisation secondaire des cadets de l'Armée de l'Air Brésilienne. À partir de la recherche de champ qualitative et documentaire, les objectifs et la pratique de cette socialisation sont discutés, avec l'accent spécial aux rapports tendus d'une institution totale (telle que définie par Erving Goffman) qui, contradictoirement,

* Doutora em Sociologia e professora de Sociologia na Universidade Federal do Rio de Janeiro (campus UFRJ-Macaé). E-mail: <giuliana_franco@hotmail.com> 
se destine à former des professionnels avec un certain degré d'autonomie individuelle. Ensuite, on discute les conséquences du processus de socialisation, celles attendues et celles pas prévues par l'institution.

Mots-clés: Socialisation secondaire. Éducation des militaires. Institution totale.

\section{Introdução}

$\mathrm{P}$ rocessos de socialização - isto é, processos por meio dos quais os indivíduos aprendem a fazer parte de uma sociedade ou de um grupo social, tomando para si elementos da cultura na qual se inserem - fazem parte da vida de todas as pessoas e são de suma importância para entender as relações sociais.

Ao ingressar num novo grupo social (por exemplo, um grupo profissional), os indivíduos passam pela socialização secundária. Certas instituições desenvolvem esse processo de modo especialmente intenso. É o caso das academias militares. $\mathrm{Ne}$ las, o processo de socialização tende a ser detalhadamente planejado para que os educandos transformem sua identidade, de modo a associá-la ao mundo militar. Além disso, o processo educativo ocorre numa instituição total, tal como descrita por Goffman (2001), ${ }^{1}$ o que tende a conduzir os cadetes (como são chamados os alunos dessas instituições) em direção a um processo de mortificação do eu (discutido ao longo do presente artigo), com consequências relevantes para as características do profissional assim formado.

Pesquisando uma academia militar brasileira - a Academia da Força Aérea (AFA) - percebemos que os objetivos formais da instituição convergem para a homogeneização dos comportamentos e dos valores em torno dos pilares do militarismo, ao mesmo tempo em que a instituição ressalta a importância de formar profissionais com espírito de iniciativa, conhecimentos específicos variados, responsabilidade e liderança, características que supõem um grau elevado de autonomia, contrário ao processo anterior. Combinando e unindo essas duas tendências aparentemente tensas e contraditórias, ocorre uma evolução na formação dos cadetes ao longo dos anos: o treinamento em liderança é progressivamente aprofundado, na medida em que liberdades vão aos poucos sendo concedidas aos militares em formação.

A partir dessas observações, temos por objetivos discutir: (a) como esses dois processos - de homogeneização e de diferenciação - se dão ao longo da formação do cadete; (b) em que medida e de que maneira eles se complementam, se confundem ou se limitam mutuamente; (c) quais são as consequências planejadas e as consequências inesperadas desse processo de socialização secundária.

A pesquisa de campo foi feita ao longo do ano letivo de 2009, por meio de entrevistas semiestruturadas, com doze cadetes no primeiro ano e dez cadetes no 
quarto (e último) ano de formação na academia, e observação participante - contando com observação sistemática em sala de aula, em outras atividades formativas (paradas militares, exercícios militares, reuniões com equipes do corpo de cadetes ${ }^{2}$ e da divisão de ensino, ${ }^{3}$ palestras e instruções) e ambientes informais (intervalos das aulas e festas) -, além de análise de documentos internos sobre a formação dos cadetes.

Não posso deixar de assinalar minha condição ambígua durante o estudo: no período da pesquisa de campo, eu era, além de pesquisadora, professora (civil) na instituição pesquisada. Essa condição, sem dúvida, muda não só o olhar da pesquisadora sobre os sujeitos observados, como também a visão destes sobre aquela. Procuro demonstrar, porém, ao longo do artigo, que essa condição não invalida os resultados da pesquisa, desde que suas implicações sejam adequadamente levadas em conta na análise.

O artigo se inicia pela descrição e discussão dos objetivos e da prática do processo de socialização dos cadetes da AFA, demonstrando como ela ocorre por uma combinação entre currículo formal e currículo oculto (ou seja, aquilo que é ensinado por atitudes, comportamentos e discursos, mas de modo não planejado formalmente) e relações informais interiores ao grupo de cadetes. Em seguida, problematizam-se as consequências dessa socialização, discutindo-se as implicações do processo para a formação do profissional na AFA.

\section{O processo de socialização dos cadetes da Academia da Força Aérea}

Quando ingressa na AFA como cadete, o jovem passa por um processo de formação que o prepara para ser um oficial da Força Aérea Brasileira. Quanto a isso, a AFA assume como missão:

[...] formar Oficiais de Carreira da Aeronáutica dos Quadros de Oficiais Aviadores (CFOAV), Intendentes (CFOINT) e de Infantaria da Aeronáutica (CFOINF), desenvolvendo em cada cadete os atributos militares, intelectuais e profissionais, além dos padrões éticos, morais, cívicos e sociais, obtendo-se, ao final deste processo, Oficiais em condições de se tornarem líderes de uma moderna Força Aérea. ${ }^{4}$

A socialização é, explicitamente, o objetivo maior da AFA, como se pode observar nos objetivos da formação, segundo o Manual do Cadete de 2010:

Desenvolver no cadete a disciplina física e intelectual, a plena compreensão de hierarquia e os ideais de coragem, lealdade, honra, dever e amor à Pátria [...]. Proporcionar ao cadete um contato e uma vivência dos princípios de conduta éticos e morais elevados e próprios da profissão militar, transmitidos pelo exemplo de seus superiores [...]. Espera-se que o cadete adquira qualidades de excelência moral que conduzem a pessoa a 
fazer a coisa certa, a despeito das pressões em contrário; [...] Desperta no cadete os mais nobres sentimentos de amor e serviço à Pátria, além de estimular o desenvolvimento da cidadania e da correção na conduta social. (AFA-CCAER, 2009a, p. 13-14)

Para que esses objetivos sejam atingidos, os cadetes passam por uma série de atividades de formação intelectual e de construção de uma ética específica do militarismo, da qual fazem parte valores pertencentes ao código de honra do corpo de cadetes (coragem, lealdade, honra, dever e pátria) ${ }^{5}$ e aos pilares do militarismo, baseados na valorização da hierarquia e da disciplina.

Existe um planejamento evolutivo do processo de socialização, com finalidades bem delimitadas. A formação se inicia pelo Programa de Treinamento Militar (PTM) ${ }_{1}^{6}$ nos dois primeiros anos, e é seguida pelo Programa de Treinamento de Liderança (PTL), ${ }^{7}$ no terceiro e quarto anos. A ideia é que se avance aos poucos na introdução da disciplina consciente, ${ }^{8}$ a cobrança seja cada vez mais individualizada e aumentem as responsabilidades e as oportunidades de liderança. No primeiro ano, são valorizadas principalmente a pronta obediência e a atenção a aspectos como pontualidade, apresentação pessoal e conduta moral. Neste período, a cobrança é intensa e depois vai se atenuando ano a ano. A partir do PTL, concede-se ao cadete certo grau de liberdade para o exercício da disciplina consciente e da liderança. ${ }^{9}$

Outro exemplo da consciência que a equipe dirigente possui do planejamento da socialização militar é a clareza, manifesta no documento sobre o Estágio de Adaptação (EAD), sobre a ordem unida constituir-se num meio de afirmação da coesão e da identidade grupal.

Quanto a isso, a antropóloga Cavilha (2009, p. 141 e 148) explica como rituais e solenidades são vitais à coletividade, ao mostrar como eles demarcam todas as entradas e saídas, sejam da jornada diária, sejam da carreira:

\footnotetext{
Desde sua entrada na instituição, o militar está sujeito às regras que se organizam nos muitos rituais e nas inúmeras "solenidades" do cotidiano. Esse treinamento instala-se num aprendizado que é, sobretudo, corporal e mediatizado pelos muito citados "manuais", numa espécie de adestramento dos movimentos que devem ser estudados e, portanto, condicionados, mas principalmente submetidos a estatutos e regras, numa tentativa de homogeneizar um modo de se comportar dentro dos quartéis [...]. Concluo que, nessas "solenidades" ritualísticas, muito além dos indivíduos envolvidos diretamente, todos se transformam em um só corpo, em um só gesto, em um só uniforme e, desse modo, personificados no grupo, em um só ideal de pertencimento.
}

Contudo, nem todas as vias de formação são formalmente planejadas. O currículo oculto também se faz presente, bem como contradições internas. Assim, é essencial observar o quanto da noção do que é ser um oficial é aprendido na interação com os colegas com mais tempo de casa, na observação dos seus comportamentos, 
nas entrelinhas dos discursos dos oficiais e nas regras da instituição que parecem servir a um fim, mas na verdade servem simultânea ou exclusivamente a outro.

Por exemplo, embora o estudo seja valorizado no discurso, outras formas de tratar o assunto o desvalorizam. Isso ocorre quando o Manual do Cadete inclui, entre as "medidas disciplinadoras especiais", atividades de estudos e de pesquisa e horários de estudo obrigatórios, que "têm como objetivo restringir parcialmente a saída do cadete da Academia (fim de semana) e ocupá-lo com estudo e aquisição de cultura geral" (AFA, 2009a, p. 30). O que fica subentendido é que o estudo é uma punição, e não algo útil e interessante.

Essa desvalorização do estudo é percebida pelos cadetes como existindo não só informalmente entre os próprios estudantes, mas também vindo "de cima para baixo". Eles comentam que é dada mais atenção a quanto seus sapatos estão engraxados do que ao cumprimento das tarefas acadêmicas, é dispensado muito mais tempo à ordem unida do que ao tempo para estudo, é "menos arriscado" estarem quietos em sala de aula nos horários de estudo obrigatório do que irem à biblioteca, pois este deslocamento pode ser uma atitude mal interpretada como estarem onde não deveriam.

$\mathrm{Na}$ escolha das formas de agir dos cadetes, destaca-se o medo de destoar. Como vários deles declararam em depoimentos informais, é frequente que prefiram não expor suas posições discordantes para não ter desavenças com os próprios colegas, nem se mostrarem muito diferentes para não serem motivos de chacota. Essa estratégia é conhecida como "ser moita", ou seja, evitar destacar-se entre os colegas para não sofrer sanções negativas informais.

É importante assinalar que o isolamento dos cadetes tem um grande peso na forma como acontece sua socialização. Nos primeiros quarenta dias, eles têm seus dias todos preenchidos por atividades e poucas horas de sono, não têm acesso à internet e estão proibidos de sair da AFA. Nos meses e anos seguintes, as proibições de saída vão se abrandando aos poucos, mas até chegarem ao quarto ano, os cadetes não estão autorizados a se ausentar da Academia, mesmo nas noites sem atividades, desde a noite de domingo até o fim da tarde de sexta-feira (com algumas exceções pontuais).

O isolamento não é apenas físico. Existe uma construção discursiva, presente nas falas dos militares em geral e mesmo dos civis que trabalham na AFA, de uma separação entre o mundo "de dentro" e "de fora". Talvez essa divisão seja tão forte por ser necessária para a formação da identidade militar em oposição à de civil, trazendo-nos de volta, mais uma vez, à questão da socialização.

De acordo com Mills (1975, p. 232), o processo de iniciação das academias militares é uma tentativa de rompimento com valores e sensibilidades antigos, em benefício da implantação de "uma estrutura de caráter o mais nova possível". 
Castro (2009), que também indicou cisão entre o mundo "de dentro" e "de fora" na Academia Militar das Agulhas Negras (Aman) - onde são formados os oficiais do Exército - na década de 1980, oferece algumas pistas sobre a relação entre esse binômio e o processo de construção da identidade militar:

\begin{abstract}
Tornar-se militar significa, acima de tudo, deixar de ser civil. A oposição entre civis e militares é estruturante da identidade militar. Ao ingressar numa academia militar, o jovem é submetido a um processo de construção da identidade militar que pressupõe e exige a desconstrução de sua identidade "civil" anterior. (p. 24-25)
\end{abstract}

Para isso, a divisão entre "dentro" e "fora" da Academia é muito forte. Os depoimentos dos cadetes da AFA, em 2009, convergem com aqueles colhidos por Castro (1990) na Aman, na década de 1980, por exemplo, nos relatos sobre sensações de descompasso entre eles e os jovens "de fora": dificuldade de ter assunto com outras pessoas, de ter as regras de etiqueta do mundo civil, de acompanhar as mudanças de ideias e valores dos antigos amigos. Parte desses cadetes conta que pretende fazer "faculdade civil" depois de formados, em parte com o objetivo de conhecer melhor esse "mundo civil" (que os cadetes da AFA chamam, às vezes, de "civilândia"). Esse descompasso não ocorre por acaso. Segundo Castro (op. cit.), quando em contato com o resto da sociedade, os cadetes passam de um mundo muito mapeado - em termos do que é "certo" e do que é "errado" e de como as coisas devem acontecer - para um mundo com diversidade e descontinuidade entre vários ethos e visões de mundo.

$\mathrm{O}$ autor sugere ainda que esse contraste com os civis, reforçando uma ideia de superioridade dos militares, é parte da afirmação da coletividade, na medida em que a sua suposta superioridade não vem de características singulares de cada militar, mas da ideia de que eles, como coletividade, "viveriam de maneira mais correta", existindo aí "uma experiência totalizadora e básica para a identidade militar: a da preeminência da coletividade sobre os indivíduos" (Castro, op. cit., p.43). Por sua vez, Leirner (1997), estudando o Exército, também percebeu essa questão da proeminência da coletividade, identificando, como seu eixo, a disciplina.

A coesão do grupo é parte dos objetivos de um "programa de formação de valores" aplicado aos cadetes da AFA em 2010. Os valores consistem em amor à profissão, hierarquia, disciplina, coragem, espírito de corpo, dignidade, dever de cidadão, patriotismo, fé na missão e amor à verdade.

Tais valores foram identificados por um grupo de estudos (formado por oficiais do Corpo de Cadetes da Aeronáutica [CCAER], pelo Capelão da Academia e por professores da Divisão de Ensino da AFA). A partir de pesquisa bibliográfica e análise da legislação vigente (principalmente o Estatuto dos Militares), o grupo chegou à definição dos valores considerados prioritários pelo CCAER. Em seguida, o grupo 
fez uma enquete com cadetes de todos os esquadrões e com oficiais de várias unidades da Aeronáutica que recebem os jovens oficiais formados pela AFA. A enquete buscava os valores que cada grupo julgava como mais importantes para o exercício da profissão militar. Foi desse conjunto de procedimentos e reflexões que surgiu a versão final dos valores a serem trabalhados com os cadetes, por meio do Programa de Formação de Valores. Em seguida, o grupo elaborou maneiras de fazê-lo, tendo como centro da atuação a fala repetida (em instruções, aulas, entre outras atividades) sobre cada um dos valores em cada mês, fazendo referência à vida cotidiana, além de palestras, cartazes e exibição de filmes e vídeos sobre os temas propostos.

É interessante que os valores escolhidos sejam considerados "inerentes à profissão das armas, tendo se demonstrado presentes e, até certo ponto, inalterados, mesmo com o passar dos séculos e das diversas modificações na estrutura social, cultural e política das civilizações" (AFA-CCAER, 2009d, p. 6). É como se houvesse valores acima da sociedade da qual se participa, algo que paira sobre o mundo, uma espécie de alma militar perene.

\section{As tensões da formação: padronização versus autonomia}

Um momento de grande importância no processo formativo do cadete é o Estágio de Adaptação (EAD), pelo qual eles passam em suas primeiras seis semanas na AFA, quando ainda são chamados de estagiários. Nesse período, recebem uma forte carga de doutrina militar e realizam uma série de atividades que os incitam à obediência, à hierarquia e à disciplina:

O EAD tem por objetivo [...] adaptar o jovem, que inicia sua jornada acadêmica, à vida da caserna e às peculiaridades da instituição, estimulando o gosto pela profissão, o espírito de corpo, a disciplina, a organização, desenvolvendo, ainda, o hábito da atividade física e do estudo, entre outras virtudes militares, com base nos mais elevados princípios éticos e morais. (AFA-CCAER, 2009e, p. 7)

Segundo o documento, o EAD tem três eixos: doutrina militar, treinamento físico e ordem unida. Na doutrina, estuda-se: o que é ser militar e, particularmente, ser um cadete; o que é a Força Aérea Brasileira (FAB), sua missão, atribuições, tarefas e funções; noções básicas sobre comando e liderança; história da FAB; personalidades consideradas importantes; "valores militares" e história militar básica. O treinamento físico, por sua, vez, tem o objetivo de adaptar os novos estagiários ao tipo de trabalho físico, militar, aplicado aos cadetes da Aeronáutica. Por fim, a ordem unida, rito em que os militares devem obedecer aos superiores quanto a modos específicos de formação do grupo e posições individuais, serve à demonstração da disciplina e da coesão, ou "espírito de corpo", do grupo (AFA-CCAER, 2009e). 
O EAD evidenciou-se na pesquisa como o período em que a socialização dos cadetes é mais intensa. Como o próprio discurso oficial da instituição exprime, o EAD é "um processo de estímulo à formação do espírito militar" (idem, ibid., p. 14). Trata-se de uma experiência de contato intenso com valores da instituição, como um rápido e profundo estágio da socialização, mas se trata também de experimentá-los para desistir deles e da carreira militar, se for o caso (AFA-CCAER, 2009e).

Temos ainda por hipótese que o EAD consiste na etapa em que a AFA mais se apresenta aos seus estudantes como instituição total, tal como definida por Goffman (2001). A partir da observação das práticas formativas dos cadetes, pode-se sugerir que as características típicas das instituições totais podem ser aplicadas à AFA, especialmente no momento do EAD.

Para começar, os estagiários não encontram, durante essas semanas em que estão proibidos de sair da instituição, a definição clara das barreiras que usualmente separam as três esferas da vida (descanso, trabalho e lazer) e que permitem às pessoas que circulem por diferentes lugares, com diferentes coparticipantes, sob diferentes autoridades; em outras palavras, todos os aspectos da vida dos estagiários são realizados nos mesmos lugares e sob uma mesma autoridade.

Como nas instituições totais típicas, cada fase da atividade diária dos participantes é realizada em grandes grupos (no caso, primeiro esquadrão), em conjunto e sob tratamento homogêneo; toda a sequência, forma e duração das atividades são estabelecidas pela equipe dirigente, por meio de um conjunto de regras formais explícitas, seguindo os princípios da hierarquia militar; as atividades são organizadas num plano racional único, com a finalidade de atender aos objetivos da instituição, tal como formalizado na missão mencionada anteriormente.

Goffman (op. cit.) mostra que o controle de necessidades humanas de um grupo grande de pessoas por meio de uma organização burocrática, tal como ocorre nas instituições totais, tem algumas consequências importantes. Ressaltaremos uma decorrência que é mais relevante para a presente pesquisa: quando as pessoas se movimentam em conjuntos, podem ser vigiadas em relação à sua obediência. Existe uma divisão básica entre um grande grupo controlado (o grupo dos internados, que vive na instituição e tem contato restrito com o mundo) e uma pequena equipe de supervisão (geralmente trabalhando durante um período do dia na instituição e mantendo contato com o mundo externo). Uma das funções dos superiores hierárquicos é o controle da comunicação entre os internados e os níveis mais elevados da equipe dirigente. Geralmente, a ausência de informações precisas dos internos sobre o que os dirigentes pretendem para eles concede aos funcionários hierarquicamente superiores a base para distância e controle sobre os internos. 
Em uma academia militar, a vigilância constante faz parte do estabelecimento e da manutenção da hierarquia. Além disso, pode-se interpretar que ela consiste num mecanismo de socialização, que tem como uma de suas bases a punição aos desvios à norma. É como no panóptico de Foucault (2008), instrumento por meio do qual aqueles que estão sob vigilância podem estar sendo observados o tempo todo por qualquer pessoa. Desse modo, o poder tem efeito constante, mesmo que não se exerça ininterruptamente, porque aumenta o número dos possíveis vigilantes e possibilita a mistura de relações de poder e de saber, tornando-se, enfim, uma função generalizada. A possibilidade constante de vigilância é um meio para manter o interno sempre atento à sua conduta, esteja ele sendo vigiado naquele momento exato ou não.

Existe uma força socializadora enorme dada pelo próprio grupo. Seguir o exemplo dos demais é uma das maneiras de ser aceito. É importante assinalar que a aceitação pelos pares é uma preocupação que emerge recorrente e espontaneamente nas entrevistas dos cadetes.

Votando às características das instituições totais, observamos que existe uma série de procedimentos na AFA, mais fortemente durante o EAD, que são típicos delas. É o caso dos processos de padronização e codificação dos ingressantes, expressos em atos como cortar o cabelo segundo um padrão, utilizar uniformes, tirar fotos, receber números pelos quais serão conhecidos. Por meio desses procedimentos, "o novato admite ser conformado e codificado num objeto que pode ser colocado na máquina administrativa do estabelecimento, modelado suavemente pelas operações de rotina" (Goffman, 2001, p. 26).

Outra característica, verificável entre aquelas apresentadas por Goffman (op. cit.) para as instituições totais, é o rebaixamento dos internos, seja por meio de posturas ou de respostas verbais de reconhecimento de sua posição hierarquicamente inferior (por exemplo, ter que se dirigir aos dirigentes com reverência o tempo todo), seja por sua exposição ao destaque público de suas características negativas, xingamentos ou gozações, ou ainda pela obrigação do trabalho repetido com minúcias que, em outras circunstâncias, seriam irrelevantes (que poderíamos exemplificar em exigências rígidas formais quanto aos formulários e documentações diários ou à aparência), podendo fazer com que os internos sintam que seu tempo e esforço têm pouco valor.

Também são características presentes na AFA, acentuadamente durante o EAD: a diminuição da privacidade, por ações como a obrigatoriedade de estar muito próximo dos outros durante todo o tempo, e a desvalorização da fala dos internados, quando não podem, por exemplo, ponderar ordens ou comentários de seus superiores que lhes pareçam injustos ou inadequados. 
Todos os procedimentos aqui descritos consistem em ataques à individualidade dos internos, na medida em que a homogeneização de sua conduta e a ruptura com seus padrões psíquicos anteriores (dadas pela quebra com os papéis desempenhados quando em maior contato com o mundo externo e a agressão à sua autoimagem) participam de um processo que Goffman (2001) chama de mortificação do eu.

Uma possível justificativa racionalizada para tal mortificação numa academia militar está no preparo para as situações de guerra, que exigem rusticidade e tolerância ao estresse. Outra hipótese de explicação seria a sua força para a criação de novas disposições internas, facilitada pela quebra das disposições anteriores, já que se trata de um processo de socialização secundária. Uma última hipótese levantada nesta pesquisa é que aquela agressão às individualidades, na medida em que permite certa homogeneização das características dos cadetes, facilita a criação de um espírito de corpo, compreendido pela instituição como um dos valores a ser cultuados. ${ }^{10}$

Para além dessas hipóteses a verificar, existe, entre as questões anteriores, uma que merece problematização: o desincentivo à autonomia dos indivíduos, a qual é parte e consequência da mortificação do eu. $\mathrm{O}$ prejuízo à autonomia dos internos, típico das instituições totais, não pode ser mantido durante toda a formação do oficial, sem prejuízo do exercício de suas funções. Vejamos por quê.

Se acompanharmos a profissionalização da ciência militar, desde o século XIX até a Guerra Fria, encontraremos algumas características importantes para um oficial das Forças Armadas. Segundo Huntington (1996), ${ }^{11}$ é tarefa do militar conhecer e saber elaborar estratégias e táticas que estejam de acordo com os objetivos definidos politicamente para o Estado nacional que ele defende. Assim, o militar tem três responsabilidades diante do Estado: 1) apresentar suas opiniões sobre as necessidades para a segurança; 2) analisar e relatar as implicações das possíveis linhas de ação do Estado sob a ótica militar; 3) executar as decisões do Estado quanto à segurança nacional, ainda que elas sejam contrárias à sua opinião (Huntington, op. cit.). Ainda segundo este autor, para que tais objetivos sejam cumpridos são necessários, além do conhecimento histórico das técnicas de organização e aplicação da força, também habilidades de análise, percepção, imaginação e julgamento.

Nesse sentido, o conhecimento do mundo em que as Forças Armadas atuam não pode ser estático, uma vez que a realidade passa constantemente por transformações. Desse modo, o bom profissional tem a obrigação de estar preparado para compreender as mudanças em processo. Principalmente desde a segunda metade do século XX, os cenários sociais têm se modificado com velocidade cada vez maior, tornando ainda mais decisiva a capacidade de questionamento e interpretação da 
realidade, na medida em que os conhecimentos se tornam também mais passíveis de mudanças. De acordo com Vidigal (2003), a incerteza quanto ao cenário social (e, portanto, às questões de segurança e defesa) implica que a formação militar deva ter em consideração que seus profissionais terão necessidade de formação permanente, continuada.

Nessa perspectiva, mais do que nunca, é necessário aprender a aprender. Além disso, vimos que faz parte das habilidades exigidas do oficial o espírito crítico, para compreender as grandes questões estratégicas do mundo, e a capacidade de iniciativa, para agir de modo pró-ativo. Tudo isso exige certo grau de autonomia, no sentido da liberdade intelectual.

Além disso, o próprio exercício da liderança - uma das características mais exaltadas do profissional que a AFA deseja formar - exige o autoconhecimento como base para a relação de influência sobre o outro. Segundo Bergamini (1994, p. 176), o líder "terá maior facilidade de chegar à compreensão do outro a partir do grau de conhecimento que tenha sobre si mesmo".

Temos aí reforçada a importância da individualidade para o oficial militar, do próprio ponto de vista da instituição, não no sentido do egoísmo ou do egocentrismo, mas na significação moderna apreendida pelo antropólogo Dumont (1985, p. 37), de acordo com a qual o indivíduo valorizado nas sociedades modernas é "o ser moral independente, autônomo [...], portador dos nossos valores supremos [da modernidade]".

Em vista desses processos ocorridos na formação dos oficiais da Aeronáutica, temos uma contradição entre, de um lado, a mortificação do eu típica das instituições totais (processada no sentido da homogeneização do grupo) e, de outro, a valorização da individualidade, como parte das exigências de perfil do oficial que se pretende formar.

É verdade que a consciência coletiva de um grupo, de um lado, e a valorização de características individuais necessárias inclusive a uma boa divisão do trabalho, de outro, não são características de todo excludentes, mas estudos clássicos da sociologia mostram que a intensificação das individualidades tende a ser acompanhada pelo enfraquecimento da consciência coletiva. ${ }^{12}$

\section{Implicações da socialização do cadete}

As respostas dos cadetes sobre terem ou não se transformado em função de sua experiência na Academia são quase unânimes. Apenas um entre todos eles, cursando o primeiro ano, declara não ter mudado em nada. Entre os demais, três 
responderam às perguntas gerais "Você mudou depois que entrou aqui, por causa da sua experiência na AFA? O que mudou?", com a afirmação de que tiveram sua personalidade mudada. Outras respostas espontâneas a essas perguntas incluem ter aprendido a "fazer o que é previsto, sempre", se tornar "mais sério, responsável", ter amadurecido, "só dar importância ao que é realmente relevante", ficar "mais centrado, mais seguro e mais prestativo", fortalecer "valores morais", ser mais rápido para cumprir suas tarefas, controlar o que diz.

Nos tópicos dirigidos das entrevistas, em que se arguiu especificamente sobre as mudanças de cada um quanto à disciplina, patriotismo, capacidade de liderança, iniciativa, criatividade, curiosidade e interesse em aprender, capacidade de buscar a própria formação e senso crítico, as respostas se dividiram.

Tanto entre os cadetes do primeiro como entre aqueles do quarto ano, cerca de dois terços afirmaram ter aumentado a disciplina e o patriotismo, mas ninguém disse que não os tinha e os criou a partir do nada. As frases típicas em resposta a esses itens foram: "eu já era disciplinado, mas aqui aprendi a ser mais ainda" ou "eu sempre fui patriota, aqui me aperfeiçoei". Ou seja, a autoavaliação dos cadetes indica que não houve criação de valores ou atitudes novas, no que se refere àqueles tópicos, mas fortalecimento de disposições que já existiam previamente.

Quanto à liderança, as respostas são bastante distintas entre os cadetes que haviam ingressado no ano da pesquisa e aqueles que estavam prestes a se formar. Os cadetes da série inicial, que só viriam a ingressar no Programa de Formação de Lideranças um ano e meio depois, afirmaram, em sua maioria (9 entre 12), que não tinham aumentado sua capacidade de liderança, ao passo que oito dos dez entrevistados do último período afirmaram que tinham ampliado sua capacidade de liderar.

No que se refere aos tópicos relativos a outras atitudes mais autônomas, por volta da metade dos cadetes, de ambos os grupos, avaliou não ter sentido melhoras. Eles afirmaram terem ficado estagnados, no total de 22 cadetes entrevistados: quanto à iniciativa (10); criatividade, (11); curiosidade sobre o mundo (10); senso crítico (11), e capacidade autônoma de formação (11). Afirmaram ainda que houve uma diminuição: na iniciativa (6); na criatividade (7); na curiosidade (7); no senso crítico (6); na capacidade autônoma de formação (6).

Seria interessante checar se as autoavaliações dos sujeitos em formação são compatíveis com as avaliações dos seus instrutores e professores, bem como dos seus colegas e superiores nos seus primeiros anos de exercício profissional após tornarem-se aspirantes e, em seguida, oficiais. Mas, por ora, teceremos nossas considerações apenas em torno da autoavaliação dos cadetes somadas às constatações da observação participante. 
Outra indicação de falhas no processo de socialização desejado pela instituição apareceu em função de um Programa de Formação de Valores, elaborado em 2009 e aplicado a partir de 2010. Em comunicação do programa aos professores, o então comandante do Corpo de Cadetes contou que este se fazia necessário porque estavam sendo observados, em parte dos cadetes, muitos comportamentos que demonstram ausência de valores prezados no meio castrense, tendo sido dado o exemplo da mentira e da necessidade de vigiar a "cola" em provas. Inclusive o documento que trata deste programa deixa clara percepção de comportamentos que representam "desvios":

\begin{abstract}
Uma série de "desvios comportamentais" ocorridos nos últimos anos no âmbito do Corpo de Cadetes e, portanto, no âmbito dos futuros oficiais da FAB foram identificados como fonte de preocupação e possibilidade de comprometimento do desempenho futuro da Força. Ao realizar uma análise mais apurada destes fatos, verificou-se que muitos iam de encontro a valores tidos como fundamentais no desempenho da profissão militar. (AFA-CCAER, 2009d, p. 6)
\end{abstract}

Desenvolvemos uma hipótese sobre as razões que contribuem para o sucesso ou o fracasso da socialização almejada pela instituição: a socialização, da maneira como a instituição a planeja, é mais eficaz na medida em que o sujeito que a sofre tem afinidade prévia com os valores ali presentes.

Ao responder sobre os motivos pelos quais escolheram a carreira militar, alguns cadetes disseram que foi por se identificarem com o militarismo, principalmente quanto à disciplina e à ordem: é o caso dos seis jovens que contaram que escolheram a carreira militar por terem "gosto da ordem, da disciplina", "da coisa certinha", "do que é previsível", a "vida regradinha", a "estabilidade financeira e geral" (profissional e familiar). Por outro lado, dois cadetes mencionaram a aventura como componentes que os haviam atraído para a vida militar.

Todos aqueles que se identificavam previamente com valores como a disciplina e a ordem consideraram-se bastante transformados pela formação militar, especialmente pelo aperfeiçoamento das características que já identificavam em si mesmos. A mesma transformação não se nota naqueles que já não se identificavam com esse tipo de valores, mas apenas com ideias como ajudar o próximo. Tudo isso sugere a dificuldade maior de internalização de valores novos e a importância da aceitação, por parte do sujeito em socialização, para que certas condutas e padrões de pensamento se incorporem com mais força à sua pessoa e à sua vida.

Entre a quase totalidade dos cadetes entrevistados (com apenas uma exceção), ouvimos a declaração de que existe uma grande diferença entre os jovens militares e os demais jovens. Foi mencionado que "a gente acaba acreditando que é diferente porque é mais provado"; "o militar tem um comportamento mais contido mesmo 
fora da organização porque ele tem que ser um exemplo", "tem que selecionar aonde ele vai, porque ele não é só ele, ele representa a instituição", "os militares são mais sérios que os civis, em tudo, principalmente nos relacionamentos", "o civil busca mais a satisfação, e o militar vai mais cumprir a missão dele", "até o jeito de andar é diferente", "o cadete tem que ter comportamento diferente, seguir o código de honra", "os jovens de fora são mais contestadores, querem mudar mais as coisas", "eles [os jovens não militares] querem é zoar", "a pressão psicológica da AFA ajuda a pessoa a se controlar melhor depois".

Existe, enfim, uma diferenciação percebida entre militares e civis, na qual geralmente o militar é visto como superior: mais sério, mais organizado, mais patriota, mais bonito em sua farda, com mais prestígio e status, especial pelas missões que cumpre. Não é raro que os cadetes repitam o que muitas vezes os oficiais dizem em seus discursos: que são uma elite. Esse pensamento, além de politicamente perigoso (como revelam os anos de ditadura em nosso país), revela uma identidade pouco democrática, na medida em que torna a diversidade indesejável.

Nas padronizações cotidianas, comentadas no item anterior deste artigo, e mesmo em documentos internos, como aquele que regula o EAD, revela-se o gosto pela homogeneidade e pela uniformidade e a negação da diversidade, como parte da formação da coesão e da identidade militar: "Esta é uma fase de acentuados treinamentos físicos e psicológicos, sendo um período que prioriza a orientação e o estímulo, visando à integração do futuro cadete a um todo harmônico e coeso, que é o Corpo de Cadetes da Aeronáutica" (AFA-CCAER, 2009e, p. 7).

Isso, aliás, vem de uma percepção (ou afirmação) da unidade numa escala maior, do próprio país, como mostra o Manual do Cadete da Aeronáutica de 2010, ao buscar uma definição para o conceito de pátria:

A Pátria não se define. Sente-se. Ela é todo esse território imenso e cheio de contrastes [...], mas, mais do que isso, é o Povo que de Norte a Sul fala a mesma língua, tem as mesmas crenças e, embora com problemas diferentes, tem sempre a mesma esperança e a mesma cordialidade. (AFA-CCAER, 2009a, p. 6)

Na busca da unidade, pode estar submersa a negação das contradições, da diferença e da diversidade. A questão da homogeneidade dos militares - pretensa ou real - em oposição aos civis leva a pensar na força de sua socialização, no sentido da formação de uma identidade:

Um ponto comum aos sociólogos que escreveram sobre as academias militares dos Estados Unidos é o destaque que dão à intensidade do processo de socialização profissional militar, combinada ao fato de que esse processo ocorre em relativo isolamento ou autonomia. Por isso, comparada a outras profissões, a militar representaria um caso- 
limite sociológico, contribuindo para uma grande coesão ou homogeneidade interna ("espírito de corpo"), mesmo que frequentemente ao preço de um distanciamento entre os militares e o mundo do civil. (Castro, 1990, p. 31)

\section{Considerações finais}

A formação do cadete, na AFA, é um processo de socialização secundária, do qual a equipe responsável tem consciência. Esses profissionais planejam um processo formativo que se inicia pela acentuação dos elementos que conduzem à padronização de comportamentos - e, nos desejos da equipe nem sempre realizados, de valores - e ataques às individualidades. Todavia, ao longo dos quatro anos de formação, abrandam-se as características de fechamento da instituição e as restrições à autonomia individual.

A socialização não se baseia apenas no currículo formalmente planejado. A pesquisa trouxe para o primeiro plano a força do currículo oculto traçado nas entrelinhas das atitudes dos oficiais, bem como o forte poder de pressão dos grupos de cadetes sobre seus pares.

Entre os sujeitos entrevistados, houve reconhecimento quase unânime de que eles passaram por transformações internas, ao longo de sua formação. Em sua percepção, disciplina é a característica que mais se acentua desde o início. Também percebem, em sua maioria, a evolução na capacidade de liderança, quando se levam em consideração apenas os cadetes prestes a se formarem, os quais já passaram por um programa específico de formação de lideranças, com dois anos de duração. Contudo, outras características referentes à autonomia individual (iniciativa, criatividade, curiosidade e senso crítico) apresentam-se nas autoavaliações de maneira dividida, entre estagnação, aumento ou decréscimo. Além disso, a própria equipe dirigente reconhece que o resultado da formação aplicada não leva necessariamente à formação de valores que eles próprios consideram essenciais ao militar.

O desejo de transformação e a identificação com certo ideal de militar têm grande peso para que a socialização se complete, mesmo que possam existir mudanças não conscientes ou não almejadas pelos indivíduos que as sofrem.

Constatou-se, nas falas e atitudes da grande maioria dos cadetes, a formação de uma identidade militar, com características próprias e, em grande medida, construídas em oposição a certa concepção do "civil" (conceito, aliás, já definido, tautologicamente, em oposição ao militar). Em parte, a identidade militar aparece, inclusive no discurso oficial, como uma necessidade da coesão da instituição. Mas é preciso considerar os erros e os perigos da crença, muito difundida em seu interior, de que ali se forma uma elite moral. 
Muitos temas, questões e problemas se evidenciam quando se inicia uma pesquisa como esta, ficando a sugestão de uma agenda de pesquisas de continuidade, aprofundamento e expansão dos estudos sobre a formação militar: os custos psicológicos do processo socializador, a relação entre as autoavaliações dos cadetes e sua evolução sob os olhos de seus superiores hierárquicos, instrutores, professores e colegas, os riscos da negação da diversidade, as consequências do distanciamento entre civis e militares e, por fim, a relação entre a formação ocorrida nas academias militares e as necessidades da sociedade.

\section{Notas}

1. “Uma instituição total pode ser definida como um local de residência e trabalho, onde um grande número de indivíduos com situação semelhante, separados da sociedade mais ampla por considerável período de tempo, levam uma vida fechada e formalmente administrada" (Goffman, 2001, p. 11).

2. Trata-se da seção responsável pela organização, apoio logístico e parte da formação militar dos cadetes.

3. Trata-se da seção responsável pelo ensino científico.

4. Disponível em: <http://afa.intraer.br>, acesso em: 2 fev. 2012.

5. Disponível em: <http://afa.intraer.br/cadetes>, acesso em: 30 jul. 2009.

6. “O PTM é a parcela da formação militar que estimula o desenvolvimento da autodisciplina, a compreensão de autoridade e hierarquia, o sentimento de camaradagem e cria fortes laços de dever e lealdade para com a instituição e o país." (AFA-CCAER, 2009b, p. 4). É um programa elaborado pela Seção de Doutrina, do Comando do $1^{\circ}$ e $2^{\circ}$ Esquadrões e da Cadeia de Liderança dos Cadetes e sua execução é supervisionada em conjunto com os Comandos do $1^{\underline{0}}$ e $2^{\circ}$ Esquadrões e Comandante do Corpo de Cadetes.

7. “Durante este programa, o cadete, por intermédio do exemplo e dos ensinamentos, vai amadurecer e conhecer suas capacidades e limitações para controlar e disciplinar a si mesmo e, com isso, liderar pessoas efetivamente, baseando-se na dignidade e no respeito" (AFA - CCAER, 2009c, p. 4). É um programa elaborado pela Seção de Doutrina, do Comando do $3^{\circ}$ e $4^{\circ}$ Esquadrões e da Cadeia de Liderança dos Cadetes.

8. Disciplina consciente "consiste no entendimento, conscientização, discernimento, vivência e prática das normas vigentes, sem necessidade de fiscalização ostensiva, no esforço pela defesa e manutenção dos ideais do sistema corrente em que o indivíduo está inserido, traduzindo, é aquela em que o 'usuário' percebe a responsabilidade por suas atitudes e comportamento" (AFA - CCAER, 2009c, p. 7).

9. “Liderança é o processo de influenciar pessoas no sentido de que ajam em prol dos objetivos da instituição" (AFA-CCAER, 2009c, p. 7).

10. Diretriz de Comando n. 01/2008, de 7 de abril de 2008, Dicom/AFA, publicada na rede interna da AFA. Disponível em: <http://afa.intraer.br>, acesso em: 30 jul. 2009.

11. Acompanhamos essa trajetória a partir do livro de Huntington (1996), que se tornou uma referência para pensar a profissão do oficial militar. Embora seu foco principal esteja nos Estados Unidos, ele se refere aos fundamentos do profissionalismo militar no mundo moderno em geral.

12. Durkheim (1984) mostrava esse processo duplo de enfraquecimento dos valores comuns na mesma medida em que aumentava a diversidade das características individuais, no conjunto da sociedade, no processo de formação da modernidade. 


\section{Referências}

ACADEMIA DA FORÇA AÉREA (AFA-FAB). Missão da AFA. [s.n.t.]. Disponível em: $<$ http://afa.intraer.br>. Acesso em: 30 jul. 2009.

ACADEMIA DA FORÇA AÉREA (AFA-CCAER). Doutrina: Manual do Cadete, 2010. Pirassununga: AFA, 2009a. (mimeo.).

ACADEMIA DA FORÇA AÉREA (AFA-CCAER). Programa de Treinamento Militar do Corpo de Cadetes da Aeronáutica. Pirassununga: AFA, 2009b. (mimeo.).

ACADEMIA DA FORÇA AÉREA (AFA-CCAER). Programa de Treinamento de Liderança do Corpo de Cadetes da Aeronáutica. Pirassununga: AFA, 2009c. (mimeo.).

ACADEMIA DA FORÇA AÉREA (AFA-CCAER). Programa de Formação de Valores. Pirassununga: AFA, 2009d. (mimeo.).

ACADEMIA DA FORÇA AÉREA (AFA-CCAER). Estágio de Adaptação. Pirassununga: AFA, 2009e. (mimeo.).

ACADEMIA DA FORÇA AÉREA (AFA-CCAER). Código de Honra do Cadete da Aeronáutica. Pirassununga: AFA, [s.d.]. (mimeo.).

BERGAMINI, C.W. Liderança: administração dos sentidos. São Paulo: Atlas, 1994.

CASTRO, C. O espírito militar: um estudo de antropologia social na Academia Militar das Agulhas Negras. Rio de Janeiro: Zahar, 1990.

CASTRO, C. Em campo com os militares. In: CASTRO, C.; LEIRNER, P. (Org.). Antropologia dos militares: reflexões sobre pesquisa de campo. Rio de Janeiro: FGV, 2009. p. 13-31.

CAVILHA, J. Das entrevistas aos rituais: dialogando com os militares. In: CASTRO, C.; LEIRNER, P. (Org.). Antropologia dos militares: reflexões sobre pesquisa de campo. Rio de Janeiro: FGV, 2009. p. 129-149.

DUMONT, L. O individualismo: uma perspectiva antropológica da ideologia moderna. Rio de Janeiro: Rocco, 1985.

DURKHEIM, É. Pedagogia e sociologia. In: DURKHEIM, É. Educação e sociologia. Rio de Janeiro: Melhoramentos, 1983.

DURKHEIM, É. A divisão do trabalho social. Lisboa: Presença, 1984.

FOUCAULT, M. Vigiar e punir: nascimento da prisão. Petrópolis: Vozes, 2008.

GOFFMAN, E. Manicômios, prisões e conventos. São Paulo: Perspectiva, 2001. 
HUNTINGTON, S.P. O soldado e o Estado: teoria e política das relações entre civis e militares. Rio de Janeiro: Biblioteca do Exército, 1996.

LEIRNER, P.C. Meia volta volver: um estudo antropológico sobre a hierarquia militar. Rio de Janeiro: FGV, 1997.

MILLS, W. A elite do poder. Rio de Janeiro: Zahar, 1975.

VIDIGAL, A.A.F. Educação, formação, cultura militar e sociedade. In: REB ELO, A.; FERNANDES, L. (Org.). Política de defesa para o século XXI. Brasília, DF: Câmara dos Deputados; Coordenação de Publicações, 2003. p. 213-223.

Recebido em 29 de fevereiro de 2012.

Aprovado em 26 de março de 2013. 